\title{
Is mucosa-associated lymphoid tissue lymphoma an infectious disease? Role of Helicobacter pylori and eradication antibiotic therapy (Review)
}

\author{
CĂTĂLINA VLĂDUȚ ${ }^{1,2}$, MIHAI CIOCÎRLAN ${ }^{1,2}$, RALUCA S. COSTACHE $^{2,3}$, MARIANA JINGA $^{2,3}$, \\ VASILE D. BALABAN ${ }^{2,3}$, DANIEL O. COSTACHE ${ }^{4}$ and MIRCEA DICULESCU ${ }^{2,5}$ \\ ${ }^{1}$ Department of Gastroenterology, 'Prof. Dr. Agrippa Ionescu' Clinical Emergency Hospital, 011356 Bucharest; \\ ${ }^{2}$ The Fifth Clinical Department, 'Carol Davila' University of Medicine and Pharmacy, 050474 Bucharest; \\ Departments of ${ }^{3}$ Gastroenterology and ${ }^{4}$ Research, 'Carol Davila' University Central Emergency Military Hospital, \\ 010825 Bucharest; ${ }^{5}$ Department of Gastroenterology, Fundeni Clinical Institute, 022328 Bucharest, Romania
}

Received June 16, 2020; Accepted July 16, 2020

DOI: $10.3892 / \mathrm{etm} .2020 .9031$

\begin{abstract}
Mucosa-associated lymphoid tissue lymphoma (MALT) is seldom considered a diagnosis hypothesis in symptomatic patients. These lymphomas present as a main risk factor for chronic gastritis due to Helicobacter pylori infection. H. pylori leads to chronic inflammation, producing lymphoid tissue in the stomach mucosa (MALT) possibly leading to malignant transformation. Even though $H$. pylori remains one of the most important factors in the development of MALT lymphoma, it is not mandatory in the evolution of MALT lymphoma since high-grade lymphomas present a lower prevalence of $H$. pylori. The prevalence of $H$. pylori is indirectly proportional with the progression into the gastric wall. Mucosal and submucosal MALT lymphomas have a higher prevalence of the bacteria. However, genetic factors remain a risk factor especially if eradication treatment fails. Even though a low percentage of MALT lymphomas are $H$. pylori-negative, some respond to antibiotic eradication treatment. This can be explained either by the immunomodulatory effect of antibiotics or by other infectious sources such as Helicobacter heilmannii and Campylobacter jejuni (small bowel lymphoma). Treatment in MALT gastric lymphoma was a breakthrough since it was the first time in oncology where tumours were cured by antibiotic therapy, leading us to wonder if MALT lymphomas are infectious disease or not?
\end{abstract}

Correspondence to: Dr Raluca S. Costache, The Fifth Clinical Department, 'Carol Davila' University of Medicine and Pharmacy, 8 Eroii Sanitari bd., 050474 Bucharest, Romania

E-mail: ralu_alf@yahoo.com

Key words: MALT, lymphoma, Helicobacter pylori, translation, infection

\section{Contents}

1. Introduction

2. Pathogenesis and immune response of Helicobacter pylori: Pathologic features of MALT lymphomas

3. Diagnosis of Helicobacter pylori infection

4. Diagnosis of MALT lymphoma

5. Treatment in gastric MALT-lymphoma associated with Helicobacter pylori

6. Surveillance

7. Conclusions

\section{Introduction}

Lymphomas are malignancies of the lymphoid systems, categorized into 2 subgroups: Hodgkin's lymphoma and non-Hodgkin's lymphomas (NHLs). In total, 1 to $4 \%$ of all gastrointestinal (GI) malignancies are lymphomas, making the GI tract the most common extranodal site of NHL. After the last update of the World Health Organization (WHO) classification, the marginal zone B-cell lymphoma (MZLs) can be categorized in extranodal MZL (EMZL) of mucosa-associated lymphoid tissue also known as MALT lymphoma, nodal MZL with or without monocytoid B cells and splenic NZL with or without villous lymphocytes $(1,2)$. MALT lymphomas represent two-thirds of MZLs. Mucosa-associated lymphoid tissue lymphoma (MALT) is represented by Peyer's patches of the terminal ileum and consists of B-cells and rare T-cells organized in different zones (3). MALT lymphoma is a subtype of non-Hodgkin lymphoma (7\% of NHL) formed from morphologically heterogeneous small B-cells including marginal zone (centrocyte-like) cells at various stages of differentiation. The true incidence of MALT lymphoma worldwide remains unclear due to the nonspecific symptoms and endoscopy findings $(4,5)$.

Newer studies link Chlamydia psittaci, Campylobacter jejuni, Borrelia afazelii and Achromobacter xylosoxidans to MALT lymphoma (2). MALT lymphoma increases the risk of gastric carcinoma by six-fold and can be associated with other 
autoimmune diseases (Sjögren or systemic lupus erythematosus) (1).

The stomach and the small intestine are the main sites of GI lymphomas. A total of $40 \%$ of gastric lymphomas are represented by gastric marginal zone B cell lymphoma of MALT, with a mean age of 60 years at the time of diagnosis, and more frequent in male patients (2-3 times more frequent than in female) (3). However, MALT lymphoma is low-grade neoplasia with an insidious evolution, often localized at the time of diagnosis. Extra-digestive sites of MALT lymphomas are parotid gland, salivary glands, ocular adnexa or thyroid gland (6).

Mostly MALT lymphomas present a large range of non-specific upper gastrointestinal symptoms (2). Endoscopy, biopsies and immunohistochemistry are the golden standards in diagnosis. Endoscopic ultrasonography (EUS) can help in determining the depth of the lesion and if there is any involvement of the peri-gastric lymph nodes and its role is significant especially in early-stage diagnosis, treatment decision and follow-up assessment. The hallmarks of MALT lymphoma are lymphoepithelial lesions, destroying the gastric glands or pits by tumour cell aggregates: Centrocyte-like cells and reactive germinal centres. One-third of the cases present atypical features such as Dutcher bodies $(7,8)$.

Chest, abdominal and pelvis computed tomography with intravenous contrast are used in staging the disease (3). Ann Arbor staging system that is routinely used in the classification of NHL is not recommended in MALT lymphoma. At present there are 2 staging systems used in GI tract lymphomas: Lugano (modified Ann Arbor staging system) and Paris (more reliable since it takes into account the depth of the infiltration, but not validated yet). However, gastric MALT lymphomas are difficult to grade (9), and often MALT lymphomas remain localized $(3,10)$.

In low-grade MALT lymphoma, the survival rate at 5 years ranges from 44 to $78 \%$, with a high chance of a curative treatment. Responding patients should undergo endoscopic surveillance since the neoplastic clone might just be suppressed not eliminated (3). Histological regression is rapid in the first 2 to 6 months, even though rare cases were reported even in 45 months. Molecular regression has a delay; therefore, PCR for monoclonal B-cells lacks specificity and follow-up should be based on endoscopy and histology (11). Recurrence can appear in Helicobacter pylori eradicated lymphoma even after remission; therefore, yearly follow-up should be indefinite. Reinfection with $H$. pylori is a possible cause of recurrence but is not mandatory $(5,12)$.

Although $10 \%$ of gastric MALT lymphomas are H.pylorinegative and that there are no guidelines in treating this subgroup, eradication treatment was proven to be the first intention. Cases from the literature show that antibiotic therapy due to its immunomodulatory effects can lead to a reaction of the B-cells. Moreover, this response is due to other infectious agents such as Helicobacter heilmannii (13-15).

\section{Pathogenesis and immune response of Helicobacter pylori: Pathologic features of MALT lymphomas}

As a first step, H. pylori colonization induces forming of lymphoid tissue in the stomach after antigen stimulation, recruiting $\mathrm{B}$ and T-cells into the gastric mucosa, to gastritis that in time evolves to low-grade MALT lymphoma and then to high-grade MALT lymphoma. H. pylori induce gastritis leading to aggregation in the gastric lamina propria of $\mathrm{CD}^{+}$ lymphocytes and B cells. Due to antigen reactivity, these cells activate and follicles form (2). Antigen stimulation leads to somatic hyper-mutation during $\mathrm{T}$ cell-dependent B-cell response and to the development of new antigen receptors with altered antigen-binding affinity. Therefore, these new B-cell clones are highly important in the early development of MALT lymphoma. Malignant transformation occurs in only a small number of patients with acquired MALT (3). High-grade gastric lymphoma is considered $H$.pylori independent growing tumours since it produces a monoclonal B-cell clone that is not antigen susceptible. High-grade gastric MALT lymphoma (stage I or limited disease) might benefit from eradication therapy for $H$. pylori, in association with chemotherapy/radiotherapy $(4,16)$.

H. pylori might express different proteins: Cytotoxin associated gene (CagA) and vacuolating cytotoxin gene (vacA) being most involved in the development of gastric lymphoma. CagA is the most studied virulence factor of $H$. pylori. Even though $70 \%$ of the strains of $H$. pylori worldwide are positive for CagA, there are certain geographical differences. Therefore, CagA positive strains reach $90-95 \%$ in East Asian countries (South Korea, China, and Japan) unlike some other countries (Australia, United States of America, England) where it is only $40 \%$ (17). CagA has many effects on host cells: Phosphorylation (in connection to Glu-Pro-Ile-Tyr-Ala (EPIYA), disruption of tight junctions and modifies cell morphology and polarity. CagA binds to and blocks the kinase activity of the partitioning-defective $1 /$ microtubule affinity-regulating kinase (Parlb/MARK2) and causes spindle dysfunction. This characteristic is more encountered in Asian strains rather than in Western strains. Recent studies show that combining the effect of CagA positive $H$. pylori strains, c-Met, E-Catherin and p-120 catenin, the bacteria can become intracellular being able to invade the cell line (18). CagA influences the development of MALT lymphomas by inhibiting the accumulation of p53 by lowering p53 transcription and inhibiting the apoptosis of B-cells (19). By suppressing JAK-STAT signalling, ectopically expressed CagA strains can suppress cellular proliferation in IL-3-dependent B-lymphoid cells. Cag A increases the expression of pro-apoptotic factor $\mathrm{p}-21$ due to CagA mediated nuclear translocation of the nuclear factor of activated T cells family transcription factor (NFATc3) (20). CagA increases cell scattering (involved in the ability of cells to spread and metastasize) by acting on the hepatocyte growth factor receptor (c-Met) that acts as an adaptor molecule for proteins such as Grb2, phospholipase CV (PLCV) and STAT3. VacA is also an important factor in H. pylori virulence; however, the mechanism by which it induces apoptosis is not completely understood. Most studies show the link between apoptosis and the low potential of mitochondrial membrane, therefore allowing to release the cytochrome $\mathrm{c}$, dropping the ATP concentration (21).

Genetic factors are significant in the development of MALT lymphoma. One of the most common genetic translocation encountered in $25-40 \%$ of cases is $t(11 ; 18)(q 21 ; q 21)$, where there is a fusion between the N-terminus of the API-r gene to 
Table I. Tests for diagnosing Helicobacter pylori infection $(1,26)$.

\begin{tabular}{|c|c|c|c|c|}
\hline Method & Type of test & Sensitivity (\%) & Specificity $(\%)$ & Test characteristics \\
\hline \multirow[t]{3}{*}{ Non-invasive } & C-urea breath test & $88-95$ & $95-100$ & $\begin{array}{l}\text { Useful in initial diagnosis and to confirm eradication } \\
\text { Uses labeled carbon isotope ( } 13 \mathrm{C} \text { non-radioactive } \\
\text { for pregnant women or children or } 14 \mathrm{C} \text { radioactive) } \\
\text { Uncommon false positive results }\end{array}$ \\
\hline & $\begin{array}{l}\text { Monoclonal stool } \\
\text { antigen test }\end{array}$ & 94 & 97 & Useful in initial diagnosis and to confirm eradication \\
\hline & Serology (IgG) & 85 & 79 & Impractical due to false positive results \\
\hline \multirow[t]{5}{*}{ Invasive } & Biopsy urease testing & $90-95$ & $90-95$ & $\begin{array}{l}\text { Can have false negative results in aforementioned } \\
\text { situations }\end{array}$ \\
\hline & Histology $^{\mathrm{a}}$ & 95 & $90-95$ & $\begin{array}{l}\text { Improved accuracy by using Giemsa or specific } \\
\text { immune stains }\end{array}$ \\
\hline & & & & $\begin{array}{l}\text { Advantage in diagnosing associated lesions } \\
\text { (atrophic gastritis, intestinal metaplasia, dysplasia, } \\
\text { MALT lymphoma) }\end{array}$ \\
\hline & Cultures & 64 & 89 & $\begin{array}{l}\text { Used in patients without response to } 2 \text { treatment } \\
\text { options }\end{array}$ \\
\hline & PCR & - & - & Only used in clinical studies \\
\hline
\end{tabular}

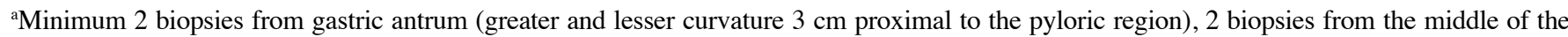
body and 1 from incisura. IgG, immunoglobulin G; PCR, polymerase chain reaction; MALT, and mucosa-associated lymphoid tissue lymphoma.

C-terminus of MALT-1 gene (that activates a nuclear factor $(\mathrm{NF}) \kappa \mathrm{B}$, a transcription factor that regulates the expression of genes involved in lymphocyte proliferation and survival). Even though this mutation decreases the response to antibiotic therapy aimed at $H$. pylori, the risk of transformation to more aggressive large cell lymphomas is lower in this case $(3,22)$. Studies emphasize the fact that $\mathrm{t}(11 ; 18)(\mathrm{q} 21 ; \mathrm{q} 21)$ mutation is not present in chronic inflammation such as $H$. pylori-associated gastritis. $\mathrm{t}(1 ; 14)(\mathrm{p} 22 ; \mathrm{q} 32)$ mutation is present in approximately $4 \%$ of gastric MALT lymphoma (23). Therefore studies emphasize the importance of determining $t(11 ; 18)(q 21 ; q 21)$ in patients with gastric MALT lymphoma (7). Other MALT lymphomas might present genetic instability due to trisomies of chromosome 3 (seen in $60 \%$ of cases), 7,12 and $18, \mathrm{t}(14 ; 18$ ) (q32;q21), t(3;14)(p13;q32) (24). Chromosomal studies are useful in patients who do not respond to therapy since the presence of trisomy 3 , BCL10 gene mutation and/or $\mathrm{t}(11 ; 18)$ can identify patients who might not respond to anti- $H$. pylori treatment (2).

Low-grade B-cell MALT lymphoma is associated with B markers $\left(\mathrm{CD}^{+}{ }^{+}, \mathrm{CD} 20^{+}\right.$and $\left.\mathrm{CD}^{2} \mathrm{a}^{+}\right), \mathrm{CD}^{2} 2^{+}, \mathrm{LN}^{-} 1^{+}, \mathrm{CD}^{-}$, $\mathrm{CD}^{-}{ }^{-}, \mathrm{CD} 23^{-}, \mathrm{IgD}^{-}, \mathrm{IgM}(>\operatorname{Ig} \mathrm{A}>\mathrm{IgG})^{+}, \mathrm{Bcl6}^{-}$(presence of Bcl6 is associated with advanced disease) and cyclin D1'. Only half of the MALT lymphomas express CD43. Ki-67 labelling index is low and can be used in the differential diagnosis with large-cell lymphoma $(6,25)$.

Interestingly, MALT lymphomas have been proved to be associated with a different infectious agent such as Chlamydia psittaci (ocular manifestations), Campylobacter jejuni (small intestinal disease), Borrelia afazelli (cutaneous manifestations) and Achromobacter xylosoxidans (pulmonary manifestations). In all these cases, antibiotic treatment must be taken into consideration $(2,26,27)$. Literature shows that large-cell transformation that results from genetic events (loss of p53 and p16) have a role in independent $H$. pylori cell growth (2).

\section{Diagnosis of Helicobacter pylori infection}

Diagnosing $H$. pylori is based on two different types of assays: i) invasive tests that are based on rapid urease test, histology, culture and PCR and ii) non-invasive tests (serology, C-urea breath test and stool antigen) are detailed in Table I. Certain limitations must be taken into consideration such as non-invasive tests can give false-negative results if taken under 6 weeks after treatment with antibiotics and bismuth and less than 2 weeks after treatment with proton pump inhibitors. Serological tests are not to be used to determine the success of the treatment since there is a gradual decline of the antibodies $(1,5)$.

Asenjo and Gisbert demonstrated that the prevalence of H. pylori in MALT lymphoma is very high, up to $90 \%$ (27). However, these percentages can vary since different methods are used to quantify the infection with $H$. pylori (28). By using two different methods, one can lower the percentage of false-negative results. Therefore, one negative result should not exclude $H$. pylori infection, but 2 negative results are required to consider a patient as non-infected (29). Since $H$. pylori mucosal colonization is uneven, the histological diagnosis has lower positive results than serological ones. Moreover, the lesions to the mucosa induced by the lymphoma might reduce the density of the bacteria. This brings to light the need for multiple biopsies. Therefore, stool antigen test or C-urea breath testing is more efficient in diagnosing this infection $(30,31)$. 
Table II. Initial work-up in suspected EMZL $(1,2)$.

\begin{tabular}{|c|c|c|}
\hline History and physical examination & Blood work & Imaging \\
\hline Lymph nodes & $\begin{array}{l}\text { Full blood count with flow cytometry } \\
\text { of peripheral blood }\end{array}$ & Chest and abdominal CT (or MRI) \\
\hline Eyes & $\begin{array}{l}\text { Biochemistry (including renal and } \\
\text { liver function) }\end{array}$ & Imaging of the orbits and salivary glands \\
\hline Nose and throat & Protein electrophoresis & PET-CT is optional \\
\hline Liver & Lactate dehydrogenase (LDH) & $\begin{array}{l}\text { EUS (depth of invasion and lymph node } \\
\text { involvement) }\end{array}$ \\
\hline Spleen & $\beta 2$ microglobulin & \\
\hline Nutritional and performance status ${ }^{\mathrm{a}}$ & HBV, HBC and HIV serology & \\
\hline
\end{tabular}

Other factors that influence the prevalence of $H$. pylori in MALT lymphoma are the histological grade of MALT lymphoma and the invasion depth. Low-grade MALT lymphoma has a higher prevalence of $H$.pylori than high-grade MALT lymphoma due to the clearance of the bacteria by the cell differentiation and blastic transformation (31).

Studies show that the prevalence of $H$. pylori is indirectly proportional with the progression into the gastric wall. Mucosal and submucosal MALT lymphoma have a higher prevalence of the bacteria than tumours extended beyond this layer (74\% vs. $44 \%$ ). Therefore, as the tumour progresses the bacteria might disappear (4).

\section{Diagnosis of MALT lymphoma}

The initial work-up of suspected EMZL is presented in Table I. Gastrointestinal symptoms that can be encountered in gastric MALT lymphoma are gastro-esophageal reflux disease, epigastric pain or discomfort, anorexia, weight loss, diarrhea, hematemesis or occult gastrointestinal bleeding. Since it can affect other organs symptoms such as malabsorption can be present (if it affects the small bowel), epiphora, ocular mass, cutaneous papules, plaques or nodules, enlarged lymph nodes. Fewer than 5\% of patients present systemic 'B symptoms' such as fever, night sweats or weight loss $(2,32)$.

PET-CT can be taken into consideration if there is a need for targeted biopsies in high-grade histology (Table II). Bone marrow aspirate is recommended in non-gastric EMZL when local treatment is taken into consideration. Bone marrow biopsy and aspirate should be performed to confirm early disease lymphoma (2). Bone marrow involvement can be seen in 2-20\% of cases and these patients present a worse prognosis (1).

Upper gastrointestinal endoscopy with biopsy, tissue histopathological analysis and immunohistochemistry remain the gold standard in diagnosing MALT lymphomas. The endoscopic view can show multiple mucosal sites as described in $25-50 \%$ of cases. Macroscopically these lesions can be heterogeneous: from single erosions to ulcerated or infiltrated masses, singular mass or multiple masses (8). It is essential to take multiple biopsies from each region of the stomach, duodenum and gastro-esophageal junction and from any abnormal mucosa. If there is suspicion of colonic MALT then a colonoscopy is mandatory (1).

Microscopic features consist in typical centrocyte-like marginal zone B-cells with small to medium-sized irregular nuclei, moderately dispersed chromatin and pale-staining cytoplasm. Immunohistochemistry should show positive CD20 and negative CD5, CD10, IgD, Cyclin D1. CD23 can be positive or negative. PCR or FISH can show negative MYD88 mutation and $\mathrm{t}(11 ; 18)$. Diagnosis and follow-up biopsies would be evaluated by a hematopathologist (1).

The International Extranodal Lymphoma Study Group has come up with a new prognostic index named MALT-IPI. It consists of 3 clinical parameters: Age $\geq 70$ years, Ann Arbor stage III or IV and elevated LDH. It can distinguish 3 groups of patients with low (no factors), intermediate ( 1 factor) and high risk (over 2 factors) with survival rates of 70,56 and $29 \%$. However, more studies are needed to validate the results (1).

Paris staging system is the most commonly used at the moment since it can also predict the response to $H$. pylori eradication, however, many guidelines use Lugano staging system as shown in Table III $(1,2)$.

\section{Treatment in gastric MALT-lymphoma associated with Helicobacter pylori}

All MALT lymphomas should receive $H$. pylori eradication treatment as a first-line treatment. In stage I-IIE Lugano classification a step-up approach is needed as seen in Table II. Regional microbial ecology should be taken into consideration when choosing eradication treatment. The most used eradication treatment for $H$. pylori remains: Amoxicillin $2 \mathrm{~g} / \mathrm{day}$, Clarithromycin $1 \mathrm{~g}$ /day and Proton Pump Inhibitors (PPI) double dose for 14 days, or in case of allergy to penicillin, metronidazole $500 \mathrm{mg}$ tid as an alternative to amoxicillin (5). The outcome of eradication therapy should be verified by non-invasive methods at least 6 weeks after the treatment (urea breath test or stool antigen test). Since clinical and endoscopic remission can be achieved in a few weeks up to one year, if persistent microscopic lymphoma is still present treatment should be initiated after 
Table III. Lugano and Paris staging system in gastric MALT lymphomas $(1,2)$.

\begin{tabular}{|c|c|c|c|}
\hline LUGANO staging system & PARIS stage & Tumor extension & Treatment \\
\hline \multirow[t]{4}{*}{ Stage I } & T1m N0 M0 & Mucosa & \multirow{10}{*}{$\begin{array}{l}\text { H.pylori eradication therapy } \\
\\
\text { H.pylori eradication therapy } \\
\text { + Systemic therapy }\end{array}$} \\
\hline & T1sm N0 M0 & Submucosa & \\
\hline & T2 N0 M0 & Muscularis propria & \\
\hline & T3 N0 M0 & Serosa & \\
\hline Stage II1 & T1-3 N1 M0 & Perigastric lymph nodes & \\
\hline Stage II2 & $\mathrm{T} 1-3 \mathrm{~N} 2 \mathrm{M} 0$ & Distant regional nodes & \\
\hline Stage IIE & T4 N0-2 M0 & $\begin{array}{l}\text { Invasion of adjacent structures with } \\
\text { or without abdominal lymph nodes }\end{array}$ & \\
\hline \multirow[t]{3}{*}{ Stage IV } & T1-4 N3 M0 & Extra-abdominal lymph nodes & \\
\hline & T1-4 N0-3 M1 & Distant GI sites involvement & \\
\hline & T1-4 N0-3 M2 & Non-GI sites involvement & \\
\hline
\end{tabular}

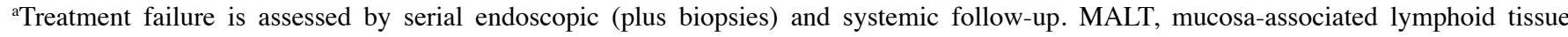
lymphoma.

Table IV. Histological response after eradication therapy in gastric MALT lymphoma (1).

\begin{tabular}{llll}
\hline Stage & \multicolumn{1}{c}{ Stromal changes } & \multicolumn{1}{c}{ Lymphoid infiltrate } & Lympho-epithelial lesion \\
\hline CR & Normal/empty and/or fibrosis & $\begin{array}{l}\text { Absent or scattered plasma cells and small } \\
\text { lymphoid cells in lamina propria }\end{array}$ & Absent \\
pMRD & Empty and/or fibrosis & $\begin{array}{l}\text { Aggregates of lymphoid cells or lymphoid } \\
\text { nodules in lamina propria/muscularis mucosa } \\
\text { and/or submucosa } \\
\text { Dense, diffuse or nodular lymphoid infiltrate }\end{array}$ & Absent \\
rRD & Focal empty LP and/or fibrosis & $\begin{array}{l}\text { extended around glands in lamina propria } \\
\text { Dense, diffuse or nodular lymphoid infiltrate }\end{array}$ & Focal or absent \\
NC & No changes & Present & \\
\hline MALT, mucosa-associated lymphoid tissue lymphoma; CR, complete histological remission; pMRD, probable minimal residual disease; rRD, \\
responding residual disease; NC, no change; LP, lamina propria.
\end{tabular}

12 months $(1,33)$. If triple therapy fails or in case of macrolide allergy or previous exposure then bismuth quadruple therapy or fluoroquinolone-containing triple or quadruple therapy (LOAD) are recommended as the second line. If second-line treatment fails, then cultures with susceptibility testing or even molecular determination of genotype resistance should be performed. In clarithromycin-resistant areas with $>15 \%$ clarithromycin resistance (Japan, Central and Southern countries of Europe) bismuth-quadruple therapy is the first-line treatment. Bismuth quadruple therapy consists in PPI (standard dose), bismuth subcitrate (120-300 mg qid) or subsalicylate (300 mg qid), tetracycline $500 \mathrm{mg}$ qid and metronidazole $250-500 \mathrm{mg}$ qid for 10-14 days. In areas with dual clarithromycin and metronidazole resistance (China) bismuth quadruple therapy is recommended as first-line. Also replacing clarithromycin with metronidazole in the triple therapy can be considered in areas with high clarithromycin resistance. Even though the cause of this resistance is still unclear, a single point mutation usually in the RDXA gene) in 1 or 4 positions of the bacterial 23S rDNA is thought to be the main reason (5). Concomitant therapy consists in: Amoxicillin 2 g/day, Clarithromycin $1 \mathrm{~g} /$ day, Nitroimidazole $1 \mathrm{~g} /$ day and
PPI (standard dose). Sequential therapy (PPI and Amoxicillin $2 \mathrm{~g} /$ day for 5-7 days followed by PPI and Clarithromycin $1 \mathrm{~g}$ /day and Nitroimidazole $1 \mathrm{~g} /$ day for the following 5-7 days) was taken into consideration, but not proven to have a greater benefit than clarithromycin-based triple therapy and is more complex leading to higher rates of drop-out $(5,6)$. Hybrid therapy represents a cross between sequential and concomitant therapies consisting of PPI and Amoxicillin for 7 days followed by PPI, amoxicillin, clarithromycin and nitroimidazole for the following 7 days. Even though this therapy was not evaluated by multiple randomized controlled trials, high cure rates in international studies promote this antibiotic therapy $(4,5,34)$. A second line quadruple regimen LOAD (Levofloxacin $250 \mathrm{mg}$ qid, PPI double dose, Nitazoxanide $500 \mathrm{mg}$ bid and doxycycline $100 \mathrm{mg}$ qid) for 14 days was proposed (5). Up to $20 \%$ of patients require a second-line treatment to eradicate $H$. pylori $(2,26)$.

Bearing in mind that the disease might act as multifocal and that sometimes clear endoscopic lesions might not be obvious, remission is considered only after 2 consecutive negative endoscopic and histological controls (at 1 and 3 months). A good histological response to eradication therapy consists 
of the regression of the diffuse lymphoid infiltrate and of the lymphoepithelial lesions (5). The terminology in assessing histological response after eradication therapy consists in: CR (complete histological remission), pMRD (probable minimal residual disease), rRD (responding residual disease), NC (no change) and is detailed in Table II after GELA staging (Group d'Etude des Lymphomes de l'Adulte) (Table IV) $(1,2)$.

Prospective studies have shown that eradication therapy for H.pylori was proven effective even in non-gastric EMLZ with partial regression of the disease. However, further studies are needed (2).

In patients who do not respond to antibiotic treatment, then irradiation and even systemic oncological therapies are mandatory. Involved-site radiotherapy is preferred in the localized disease that does not respond to antibiotics and in localized relapsing disease: moderate use (24-30 Gy to the stomach and perigastric nodes) over 3-4 weeks (1). Less than 5\% of patients treated with radiotherapy do not present CR (2). If systemic treatment should be associated then chemo-immunotherapy can be used (1).

Chemotherapy, immunotherapy or a combination of these two are efficient in patients with symptomatic systemic disease, contraindication to radiotherapy, failure after antibiotics or after local therapy (surgery or radiotherapy), overt progression, deep invasion, bulky disease, impending organ damage or even patient preference but always after eradication therapy for $H$. pylori. Alkylating agents (cyclophosphamide or chlorambucil) or purine nucleoside analogues (cladribine or fludarabine) are efficient (1). In advanced disease rituximab (anti-CD-20 monoclonal antibody) is the hallmark of treatment with an overall and complete response rate of 77 and $46 \%(2,3)$. Rituximab therapy is well tolerated, though HBs Ag and anti-HBc antibodies should be tested first due to the risk of HBV reactivation associated with rituximab. Remission was more probable in MALT lymphoma confined to the submucosa and in the distal stomach rather than proximal. However, there are undergoing studies that show good promise in associating rituximab and lenalidomide or rituximab and bendamustine. Chlorambucil should not be used to consolidate treatment after a good response to $H$. pylori eradication therapy. In patients with very aggressive clinical course and suspected histological transformation, the first option of treatment is chemotherapy as mentioned in the guidelines for diffuse large B-cell lymphoma $(1,35)$. Moreover, the cell ration $\mathrm{FOXP}^{+} / \mathrm{CD}^{+}$ $\mathrm{T}$-cells and the absolute number of FOXP3 ${ }^{+}$cells were proved to be higher in responders to eradication therapy of $H$. pylori rather than in non-responders $(33,36,37)$. On the contrary, over-expression of miR-142-5p (hematopoietic specific micro-RNA) or miR-155 (potential oncogenic microRNA) was correlated to a lower chance to respond to eradication therapy $(38,39)$. Experimental data suggest using vascular endothelial growth factor (VEGF) as a targeted therapy for MALT lymphoma, but further studies are needed (40). Studies are still needed for ibrutinib and copanlisib (phosphoinositide 2-kinase inhibitor) in patients with recurrence after one prior systemic anti-CD20-based therapy. Enrolment in clinical trials should be an option for patients not responding to treatment $(1,41)$.

Surgical treatment is nowadays restricted to the management of cases with complicated disease: Perforation or bleeding that cannot be controlled endoscopically (1).
In stage I, 75\% of MALT lymphoma will achieve complete remission, $25 \%$ of patients do not respond to $H$. pylori eradication treatment thus preventing treatment failure. In these cases, genetic tests are in order since $t(11 ; 18)$ is commonly associated. Studies have shown that even in $H$. pylori-negative cases antibiotic treatment can be worthwhile since other Helicobacter species can be involved in the pathogenesis. However, if the treatment fails in these cases with no H.pylori infection, specific anti-lymphoma treatment should be started immediately and not wait 12 months. The option in this situation should be purine analogues or rituximab since there is little to no response to alkylating agents (1).

\section{Surveillance}

Surveillance is done by systemic follow-up and endoscopy and gastric biopsies to exclude persistent disease or early epithelial changes leading to gastric carcinoma. GELA staging is useful and standardized in the accurate follow-up of patients. Endoscopy should be performed at 3 months after eradication of $H$. pylori to observe CR and then twice per year for 2 years and then every 12-18 months. Even though transient histological relapses can often be seen in endoscopy, the definition of relapse should be made after sustained and progressive histological modification (at 2 consecutive endoscopies). If stable residual disease is seen then a watch-and-wait policy is safe $(1,2)$.

\section{Conclusions}

MALT lymphomas are associated in more than $90 \%$ of cases with $H$. pylori infection. These bacteria induce the production of lymphoid tissue into the stomach after antigenic stimulation and lymphoepithelial lesions might occur leading to lymphoma (low-grade at first, evolving to high-grade). H. pylori eradication therapy is mandatory in any case of MALT lymphoma: as sole therapy in responsive localized disease or associated with chemotherapy, radiotherapy or even surgery. In patients that do not respond to triple therapy-genetic alterations might be the cause: $\mathrm{t}(11 ; 18)$. Due to the molecular, genetic and biological impact of $H$. pylori, gastric MALT lymphoma could be considered an infectious disease. Moreover, having discovered different bacteria that are involved in the pathogenesis of extragastric MALT lymphoma raises numerous questions about the real impact of antibiotherapy in MALT lymphomas therefore further extensive studies are needed. Even in this remains a rare pathology more clinical trials are needed to discover more curative molecules.

\section{Acknowledgements}

Not applicable.

\section{Funding}

No funding was received.

\section{Availability of data and materials}

Not applicable. 


\section{Authors' contributions}

$\mathrm{CV}$ conceived and designed the study, and acquired the data. MC conceived and design the study. RSC edited the final draft, validated and interpreted the data. MJ validated and interpreted the data. VDB performed statistical analysis and data management. DOC interpreted the data and edited the final draft. MD coordinated the study and validated the final data. All authors read and approved the final version of the manuscript.

\section{Ethics approval and consent to participate}

Not applicable.

\section{Patient consent for publication}

Not applicable.

\section{Competing interests}

The authors declare that they have no competing interests.

\section{References}

1. Zucca E, Arcaini L, Buske C, Johnson PW, Ponzoni M, Raderer M, Salar A, Stamatopoulos K, Thieblemont C, Wotherspoon A, et al: Marginal zone lymphomas: ESMO Clinical Practice Guidelines for diagnosis, treatment and follow-up. Ann Oncol 31: 17-29, 2020.

2. Uptodate.com accessed on 19.05.2020.

3. Feldman M and Lawrence JB: Sleisenger and Fordtran's gastrointestinal and liver disease. 10th edition, Philadelphia, Elsevier Saunders, pp473-477, 2015.

4. Chan AO, Chu KM, Yuen ST, Leung SY, Lam SK and Wong J: Synchronous gastric adenocarcinoma and mucosa-associated lymphoid tissue lymphoma in association with Helicobacter pylori infection: Comparing reported cases between the East and West. Am J Gastroenterol 96: 1922-1924, 2001.

5. Gisbert JP and Calvet X: Common misconceptions in the management of Helicobacter pylori-associated gastric MALTlymphoma. Aliment Pharmacol Ther 34: 1047-1062, 2011.

6. Podolsky DK, Camilleri M, Fitz G, Kalloo AN and Shanahan F, (eds): Yamada's Textbook of Gastroenterology. 6th edition, Sussex, Wiley Blackwell, 1123, 1332, 1341, 1574, 2016.

7. Bacon CM, Ming-Qing D and Dogan A: Mucosa-associated lymphoid tissue (MALT) lymphoma: A practical guide for pathologists. J Clin Pathol 60: 361-72, 2007.

8. Isaacson PG, Berger F, Muller-Hermelink HK, Nathwani BN, Piris MA, Swerdlow SH, et al: Extranodal marginal zone B-cell lymphoma of mucosa-associated lymphoid tissue (MALT lymphoma). In: Jaffe ES, Harris NL, Stein H and Vardiman JW, (eds). World Health Organization classification of tumours, Tumours of haematopoietic and lymphoid tissues. Lyon, IARC Press, pp157-160, 2001

9. Ruskoné-Fourmestraux A,Dragosics B,Morgner A,Wotherspoon A and de Jong D: Paris staging system for primary gastrointestinal lymphomas. Gut 52: 912-913, 2003.

10. Musshoff K: Clinical staging classification of non-Hodgkin's lymphomas (author's transl). Strahlentherapie 153: 218-221: 1977 (In German).

11. Stathis A, Chini C, Bertoni F, Proserpio I, Capella C, Mazzucchelli L, Pedrinis E, Cavalli F, Pinotti G and Zucca E: Long-term outcome following Helicobacter pylori eradication in a retrospective study of 105 patients with localized gastric marginal zone B-cell lymphoma of MALT type. Ann Oncol 20 : 1086-1093, 2009.

12. Hong SS, Jung HY, Choi KD, Song HJ, Lee GH, Oh TH, Jo JY, Kim KJ, Byeon JS, Myung SJ, et al: A prospective analysis of low-grade gastric malt lymphoma after Helicobacter pylori eradication. Helicobacter 11: 569-573, 2006.
13. Raderer M, Streubel B, Wohrer S,Häfner M and Chott A: Successful antibiotic treatment of Helicobacter pylori negative gastric mucosa associated lymphoid tissue lymphomas. Gut 55: 616-618, 2006.

14. Park HS, Kim YJ, Yang WI,Suh CO and Lee YC: Treatment outcome of localized Helicobacter pylori-negative low-grade gastric MALT lymphoma. World J Gastroenterol 16: 2158-2162, 2010.

15. Negrut N, Khan SA, Bungau S, Zaha DC, Anca CAR, Bratu O, Diaconu CC and Ionita-Radu F: Diagnostic challenges in gastrointestinal infections. Rom J Mil Med CXXIII: 83-90, 2020

16. Ferreri AJ, Freschi M, Dell'Oro S, Viale E, Villa E and Ponzoni M: Prognostic significance of the histopathologic recognition of low- and high-grade components in stage I-II B-cell gastric lymphomas. Am J Surg Pathol 25: 95-102, 2001.

17. Hatakeyama M: Helicobacter pylori CagA - a bacterial intruder conspiring gastric carcinogenesis. Int J Cancer 119: 1217-1223, 2006.

18. Oliveira MJ, Costa AM, Costa AC, Ferreira RM, Sampaio P, Machado JC, Seruca R, Mareel M and Figueiredo C: CagA associates with c-Met, E-cadherin, and p120-catenin in a multiproteic complex that suppresses Helicobacter pylori-induced cell-invasive phenotype. J Infect Dis 200: 745-755, 2009.

19. Umehara S, Higashi H, Ohnishi N, Asaka M and Hatakeyama M: Effects of Helicobacter pylori CagA protein on the growth and survival of B lymphocytes, the origin of MALT lymphoma. Oncogene 22: 8337-8342, 2003.

20. Yokoyama K, Higashi H, Ishikawa S, Fujii Y, Kondo S, Kato H, Azuma T, Wada A, Hirayama T, Aburatani H and Hatakeyama M: Functional antagonism between Helicobacter pylori CagA and vacuolating toxin VacA in control of the NFAT signaling pathway in gastric epithelial cells. Proc Natl Acad Sci USA 102: 9661-9666, 2005.

21. Jones KR, Whitmire JM and Merrell SD: A tale of two toxins: Helicobacter pylori CagA and VacA modulate host pathways that impact disease. Front Microbiol 1: 115, 2010.

22. Dierlamm J, Baens M, Wlodarska I, Stefanova-Ouzounova M, Hernandez JM, Hossfeld DK, De Wolf-Peeters C, Hagemeijer A, Van den Berghe $\mathrm{H}$ and Marynen P: The apoptosis inhibitor gene API 2 and a novel $18 \mathrm{q}$ gene, MLT, are recurrently rearranged in the $\mathrm{t}(11 ; 18)(\mathrm{q} 21 ; \mathrm{q} 21)$ with mucosa-associated lymphoid tissue lymphomas. Blood 93: 3601-3609, 1999.

23. Takada S, Yoshino T, Taniwaki M, Nakamura N, Nakamine H, Oshima K, Sadahira Y, Inagaki H, Oshima K and Tadaatsu A: Involvement of the chromosomal translocation $\mathrm{t}(11 ; 18)$ in some MALT lymphomas and diffuse large B-cell lymphomas of the ocular adnexa: Evidence from multiplex rTP chain reaction and fluorescence in situ hybridization on using formalin-fixed, paraffin-embedded specimens. Mod Pathol 16: 445-452, 2003.

24. Kasper DL, Hauser S, Jameson L, Fauci AS and Longo DL: Harrison's principles of internal medicine. 19th edition Vol. 2. N.p: McGraw-Hill Education 2 vols. 697: 702-703, 1038-1042, 2015.

25. Wotherspoon AC: A critical review of the effect of Helicobacter pylori eradication on gastric MALT lymphoma. Curr Gastroenterol Rep 2: 494-498, 2000.

26. Malfertheiner P,Megraud F, O'Morain CA, Gisbert JP, Kuipers EJ, Axon AT, Bazzoli F, Gasbarrini A, Atherton J, Graham DY, et al: Management of Helicobacter pylori infection - the Maastricht V/Florence consensus report. Gut 66: 6-30, 2017.

27. Asenjo LM and Gisbert JP: Prevalence of Helicobacter pylori infection in gastric MALT lymphoma: A systematic review. Rev Esp Enferm Dig 99: 398-404, 2007 (In Spanish).

28. Iftimie G, Pantea Stoian A, Socea B, Motofei I, Marcu D, Costache RS and Diaconu C: Complications of systemic lupus erythematosus: A review. Rom J Mil Med CXXI: 9-15, 2018.

29. Chiang IP, Wang HH, Cheng AL, Lin JT and Su IJ: Low-grade gastric B-cell lymphoma of mucosa-associated lymphoid tissue: Clinicopathologic analysis of 19 cases. J Formos Med Assoc 95: 857-65, 1996.

30. Lehours P, Ruskone-Fourmestraux A, Lavergne A, Cantet F and Mégraud F; Groupe d'Etude des Lymphomes Digestifs (GELD) for the Fédération Française de Cancérologie Digestive (FFCD): Which test to use to detect Helicobacter pylori infection in patients with low-grade gastric mucosa-associated lymphoid tissue lymphoma? Am J Gastroenterol 98: 291-295, 2003.

31. Bouzourene H, Haefliger T, Delacretaz F and Saraga E: The role of Helicobacter pylori in primary gastric MALT lymphoma. Histopathology 34: 118-123, 1999.

32. Draghici T, Negreanu L, Bratu OG, Pantea Stoian A, Socea B, Neagu TP, Stanescu AMA, Manuc D and Diaconu CC: Paraneoplastic syndromes in digestive tumors: A review. Rom Bio Lett 24: 813-819, 2019. 
33. Montalban C and Norman F: Treatment of gastric mucosa-associated lymphoid tissue lymphoma: Helicobacter pylori eradication and beyond. Expert Rev Anticancer Ther 6: 361-371, 2006.

34. Diaconu C, Ioniță Radu F, Jinga M, Nuță P, Bucurică S, Macadon B, Pătrășescu M, Popescu A, Balaban V, Voicu L, et al: From liver biopsy to non-invasive markers in evaluating fibrosis in chronic liver disease. Rom J Mil Med 108: 5-12, 2015.

35. Ion A, Popa IM, Papagheorghe LML, Lisievici C, Lupu M, Voiculescu V, Caruntu C and Boda D: Proteomic approaches to biomarker discovery in cutaneous T-cell lymphoma. Dis Markers 2016: 9602472, 2016.

36. García M, Bellosillo B, Sánchez-González B, García-Payarols F, Seoane A, Ferrer AM, Gimeno E, Barranco LE, Torner A Solé F, et al: Study of regulatory T-cells in patients with gastric MALT lymphoma: influence on treatment response and outcome. PLoS One 7: e51681, 2012.

37. Cioplea M, Caruntu C,Zurac S, Bastian A, Sticlaru L, Cioroianu A, Boda D, Jugulete G, Nichita L and Popp C: Dendritic cell distribution in mycosis fungoides vs. inflammatory dermatosis and other T-cell skin lymphoma. Oncol Lett 17: 4055-4059, 2019.
38. Saito Y, Suzuki H, Tsugawa H, Imaeda H, Matsuzaki J, Hirata K, Hosoe N, Nakamura M, Mukai M, Saito H and Hibi T: Overexpression of miR-1425p and miR-155 in gastric Mucosa-associated lymphoid tissue (MALT) lymphoma resistant to Helicobacter pylori eradication. PLoS One 7: e47396, 2012.

39. Boda D: Cellomics as integrative omics for cancer. Curr Proteomics 10: 237-245, 2013.

40. Nakamura M,Takahashi T, Matsui H, Takahashi S, Murayama SY, Suzuki $\mathrm{H}$ and Tsuchimoto K: New pharmaceutical treatment of gastric MALT lymphoma: Anti-angiogenesis treatment using VEGF receptor antibodies and celecoxib. Curr Pharm Des 20: 1097-1103, 2014.

41. Surcel M, Huica RI, Munteanu AN, Isvoranu G, Pirvu IR, Ciotaru D, Constantin C, Bratu O, Caruntu C, Neagu M and Ursaciuc C: Phenotypic changes of lymphocyte populations in psoriasiform dermatitis animal model. Exp Ther Med 17: 1030-1038, 2019. 